\title{
Incorporating spatial autocorrelation in rarefaction methods: implications for ecologists and conservation biologists
}

\author{
Giovanni Bacaro $^{1 *}$, Alfredo Altobelli ${ }^{1}$, Michela Cameletti ${ }^{2}$, Daniela Ciccarelli ${ }^{3}$, Stefano \\ Martellos ${ }^{1}$, Michael W. Palmer ${ }^{4}$, Carlo Ricotta ${ }^{5}$, Duccio Rocchini ${ }^{6}$, Samuel M. Scheiner ${ }^{7}$, \\ Enrico Tordoni ${ }^{1}$, Alessandro Chiarucci ${ }^{8}$
}

${ }^{1}$ Department of Life Sciences, University of Trieste, Via L. Giorgieri 10, 34127 Trieste, Italy;

${ }^{2}$ Department of Management, Economics and Quantitative Methods, University of Bergamo, Italy.

${ }^{3}$ Department of Biology, University of Pisa, Via Luca Ghini 13, 56126 Pisa, Italy;

${ }^{4}$ Department of Plant Biology, Ecology and Evolution, Oklahoma State University, Stillwater, OK 74078 USA

${ }^{5}$ Department of Environmental Biology, University of Rome 'La Sapienza', Rome, Italy

${ }^{6}$ Department of Biodiversity and Molecular Ecology, Fondazione Edmund Mach, Research and Innovation Centre, Via Mach 1, 38010 San Michele all'Adige (TN), Italy;

${ }^{7}$ Division of Environmental Biology, National Science Foundation, 4201 Wilson Blvd., Arlington, VA 22230, USA

${ }^{8}$ Department of Biological, Geological and Environmental Sciences, Alma Mater Studiorum University of Bologna, Via Irnerio 42, 40126, Bologna, Italy.

*corresponding author: gbacaro@units.it 


\begin{abstract}
Recently, methods for constructing Spatially Explicit Rarefaction (SER) curves have been introduced in the scientific literature to describe the relation between the recorded species richness and sampling effort and taking into account for the spatial autocorrelation in the data. Despite these methodological advances, the use of SERs has not become routine and ecologists continue to use rarefaction methods that are not spatially explicit. Using two study cases from Italian vegetation surveys, we demonstrate that classic rarefaction methods that do not account for spatial structure can produce inaccurate results. Furthermore, our goal in this paper is to demonstrate how SERs can overcome the problem of spatial autocorrelation in the analysis of plant or animal communities. Our analyses demonstrate that using a spatially-explicit method for constructing rarefaction curves can substantially alter estimates of relative species richness. For both analyzed data sets, we found that the rank ordering of standardized species richness estimates was reversed between the two methods. We strongly advise the use of spatiallyexplicit rarefaction methods when analyzing biodiversity: the inclusion of spatial autocorrelation into rarefaction analyses can substantially alter conclusions and change the way we might prioritize or manage nature reserves.
\end{abstract}

Keywords: Biodiversity, Coastal Dune Vegetation, Conservation, Rarefaction Curves, Reserve Selection, Site of Community Importance, Spatial Autocorrelation, Spatially Explicit Rarefaction.

Abbreviations: RC - Rarefaction Curve; SA - Spatial Autocorrelation; SER - Spatially Explicit Rarefaction; SCI - Site of Community Importance. 


\section{INTRODUCTION}

Biogeography and ecology are deeply permeated by the spatial nature of their data (Legendre, 1993). Several types of spatial analysis and statistics are routinely used to determine how spatial structure affects the movement of individuals, species distributions, the structure and composition of species assemblages, and to predict the consequences of spatial heterogeneity (Fortin et al. 2012). Georeferenced data are increasingly available (e.g., Martellos and Attorre 2012) and are being used to address pressing planetary challenges from climate change and increased human-driven land use. Such uses require spatio-temporal analyses that take into account the spatial and temporal extent and grain of the data (Fortin et al. 2012, Bacaro et al. 2012).

Traditionally, the analysis of species richness at relatively large extents has relied on the use of standardized sampling at smaller extents combined with the use of statistical estimators for extrapolating to larger extents (D’Alessandro and Fattorini 2002; Chiarucci et al. 2003; Chiarucci et al. 2011). However, robust methods for such extrapolation are not routinely used. The development of methods for such sampling and extrapolation offers new challenges and opportunities (Palmer et al. 2002; Engemann et al. 2015). Rarefaction curves (RCs) have been extensively used to compare species richness among very different types of habitat and biota (e.g., Heilmann-Clausen and Christensen 2004; Schneider and Culver 2005; Sogin et al. 2006; Roesch et al. 2007; Koellner et al. 2004; Chiarucci et al 2008b; Acosta et al. 2008, Bacaro et al. 2012). Rarefaction allows comparisons of species richness among data sets by standardizing estimates to an equal-effort basis. Species richness estimates increase with the number of sampling units (e.g., plots, traps; Fairbanks and McGwire 2004). Therefore, a suitable comparison of species richness estimated from data sets of different sample sizes should be done only after rarefying each to the an equal sampling effort, such as area or number of sampling units (Gotelli and Colwell 2001). Depending on the units used to express sampling effort, i.e., the number of individuals sampled or the number of sampling units, it is possible to calculate either individual- or 
sample-based rarefaction curves.

Formally, given a collection of $n$ sampling units, sample-based rarefaction provides the expected number of accumulated species as the number of sampling units increases from 1 to $n$. This is often obtained by repeatedly resampling the pool of $n$ sampling units at random without replacement and plotting the average number of species recorded by $1,2, \ldots, n$ sampling units (Gotelli and Colwell 2001).

An analytical formulation for the calculation of the rarefaction curve was first developed by Shinozaki (1963,), and later independently rediscovered by a number of authors during the 1970s (Kobayashi 1974; Holthe 1975; Engen 1976; Smith et al. 1979) and in the last decade (Ugland et al. 2003; Colwell et al. 2004). Chiarucci et al. (2008a) described the history of the multiple discoveries of sample-based rarefaction as a classical example of geographical and linguistic bias in scientific literature. If $\boldsymbol{G}$ denotes the set of species observed in the collection of $n$ sampling units, $S_{n}$ denotes the total number of observed species, and $n_{k}$ denotes the number of sampling units containing at least one individual of species $\boldsymbol{k} \in \boldsymbol{G}$, then, the expected number of species $S i$ is:

$$
S_{i \sqcup}=S_{n}-\left(\begin{array}{l}
n \\
i
\end{array}\right)^{-1} \sum_{k \in G}\left(\begin{array}{c}
n-n_{k} \\
i
\end{array}\right) i=1, \ldots, n
$$

This equation describes the expectation of $S_{i}$ when $i$ samples are randomly resampled without replacement (Chiarucci et al. 2008a). This estimator is unbiased if the spatial distribution of individuals is random (Kobayashi 1982; Gotelli and Colwell 2001; Collins and Simberloff 2009) and it can be used for comparisons among data sets if sample sizes are sufficient and the data sets were sampled in a similar way (Abele \& Walters 1979). The latter two requirements are easy to control and or adjust for either in the initial sampling design or in choosing which data sets to compare. However, individuals are almost never randomly distributed in space, either due to heterogeneity of environmental factors or non-random dispersal of individuals. Thus, it is necessary to develop rarefaction methods that account 
for such non-random distributions.

Recently, Chiarucci et al. (2009) defined a new type of rarefaction curve, termed Spatially Constrained Rarefaction (SCR) that accounts for the spatially-autocorrelated structure of biological communities. In this paper we refer to this method by the somewhat more accurate name of Spatially Explicit Rarefaction (SER). This method addressed the problem of spatial autocorrelation by building the rarefaction curve based on the adjacency of the sampling units (see Chiarucci et al. 2009 for a full description of the rationale and method). More recently, Bacaro et al. (2012a) developed "pointpattern" and "SCR" routines in the R environment for calculating a SER, making this technique readily available. To our knowledge, however, the use of SERs has not become routine (a recent ecological application can be found in Janisova et al. 2014). Conversely, a plethora of recent studies (e.g., Hardersen and Corezzola 2014; Siegloch et al. 2014; Brazee et al. 2014; Jung et al. 2014; Giesecke et al. 2014, Xu et al. 2014a; Xu et al. 2014b) and statistical software (see, for example, Oksanen et al. 2015; Cardoso et al. 2015) continue to use nonspatially-explicit rarefaction methods. In this paper, we aim at demonstrating how SERs can overcome the problem of spatial autocorrelation in the analysis of plant or animal communities.

\section{Case Studies}

To illustrate how the two methods (RCs and SERs) differ in practice and why spatially-explicit rarefactions should be preferred, we re-analyzed two published vegetation datasets (Ciccarelli 2014; Chiarucci et al. 2008a). The examples differ both in sampling strategies and vegetation type, and demonstrate the generality of our conclusions.

\section{Example 1: coastal dune plant communities}

The first example was a vegetation survey carried out on coastal dune plant communities. Dune 
ecosystems are diverse in terms of both environmental heterogeneity and species composition (Van Der Maarel 2003; Martínez and Psuty 2004). Furthermore, the dynamic nature of sandy coastal habitats, together with the strong zonation patterns exhibited by the vegetation make dune communities the focus of several national and international conservation efforts and policies. We analyzed a set of plots collected in the coastal sand dunes of two Protected Areas (PA) along the Tuscan littoral of Italy (Fig. 1): Migliarino-San Rossore-Massaciuccoli Regional Park (MSRM) and Maremma Regional Park (MP). The coastal dune ecosystems of both parks are part of the Natura 2000 network. Plant species data were collected using a systematic sampling design. In each protected area, the entire coastal system $(20 \mathrm{~km}$ and $10 \mathrm{~km}$ in length for MSRM and MP parks, respectively) was divided into sections of $1 \mathrm{~km}$. Within each section (13 for MSRM and 7 for MP) a transect was randomly located orthogonal to the seashore. The lengths of the transects varied depending on dune morphology and width. Along each transect, species presences were recorded in contiguous $1 \mathrm{~m} \times 1 \mathrm{~m}$ plots. Sampling occurred between May 2010 and August 2011; for further details, see Ciccarelli (2014). For each park, classic rarefaction curves (RCs) and spatially-explicit rarefaction curves (SERs) were calculated. For RCs we used the "specaccum" function within the "vegan" R package (Oksanen et al. 2015). For SERs we used the R routines "pointpattern" and "SCR" (Bacaro et al. 2012a). From a practical point of view, SERs are constructed by accumulating species of nearest plots for the given $n$ number of plots sampled. This is done by firstly ordering plots according to their minimum distance and then performing an accumulation curve for each ordered sequence. The rarefaction curve (SER) was then calculated as the mean of the $n$ accumulation curves.

As expected, the larger area sampled in the MSRM compared to the MP area resulted in a higher observed species richness (53 vs. 39 species, respectively; Table 1). Figure 2 compares the RCs and SERs for the two parks. As expected, the SERs increased less steeply than the RCs resulting in lower estimates of species richness at a given extent. Notably, at any given extent, the relative ranking of the 
two parks was reversed for the two methods and, overall the RC method always estimated higher species richness than the SER method (Table 1). Typically in rarefaction analyses, species richness estimates are standardized at the sample size of the smaller data sets, which was 305 plots for these data. At that extent, the RC method estimated a species richness of 44.9 for MSMR compared to the total of 39 species observed for MP. In contrast, the SER method estimated only 34.6 species for the MSMR. Thus by accounting for spatial structure, we can conclude that the MP is more diversified than the MSMR. This example shows how the inclusion of spatial autocorrelation into rarefaction analyses can alter conclusions and eventually even change the way we might prioritize or manage nature reserves.

\section{Example 2: Sites of Community Importance}

The second example was a survey of plant species occurrence within the Sites of Community Importance (SCIs) of the Province of Siena, Italy. The complete survey is described in Chiarucci et al. (2012) and a subset of these data was previously analyzed in Chiarucci et al. (2008b). The dataset consists of 604 vegetation plots collected across the entire network of 17 SCIs (Figure 3). A grid of 1 $\mathrm{km} \times 1 \mathrm{~km}$ cells were laid across the network and a random point selected within each; plant presences were recorded for a $10 \times 10 \mathrm{~m}$ plot centered at each point. For this paper, we analysed data from three SCIs (Table 1): Montagnola Senese (MNS), Crete dell'Orcia e del Formone (FOR), and Castelvecchio (CAS). The three SCIs differ for main land-cover types: thermophilous oak forests, mesophilous oak forests and Castanea sativa dominated forests (MNS), agricultural areas, dry grasslands, pastures, badland vegetation, shrublands and riverbed vegetation (FOR), and thermophilous deciduous forest and evergreen forests (CAS).

SERs and RCs were calculated as in the first example. Similar to the other example, the rank orderings of the curves produced by the two methods were reversed (Figure 4). For the estimate of species 
richness at the common sampling effort (11 plots), using RCs the species richness ranking was FOR (201.3 species), MNS (195.5 species) and CAS (191 species); SERs produced exactly the opposite ordering, CAS (191 species), MNS (187.8 species) and FOR (167.4 species). Again, rarefaction methods were shown to be susceptible to spatial autocorrelation.

\section{Discussion}

Our analyses demonstrate that using a spatially-explicit method for constructing rarefaction curves can substantially alter estimates of relative species richness. It is just as important to consider spatial autocorrelation as it is to note data extent and grain for such comparisons. The analysis of how the spatial configuration of sampling units influences species richness estimates has become an important issue (Kühn 2007) because species richness is one of the simplest and most popular diversity measures, with intuitive mathematical and statistical properties (Chao and Jost 2012; Chiarucci et al., 2011). Our results do not indicate that all previous analyses that used or compared RCs are flawed. However, as stated by Kühn (2007), "if spatial autocorrelation is ignored we simply do not know if we can trust the results at all." Therefore, the presence of residual spatial autocorrelation should always be tested for in spatial ecology and appropriate methods should be used if there is evidence of a significant spatial autocorrelation (Cressie 1993; Fortin and Dale 2009, Fortin et al. 2012). Spatially-explicit methods should routinely be used in rarefaction analyses and be included in the development of new methods. Recently, both functional (Ricotta et al. 2012) and phylogenetic rarefactions (Chao et al. 2015) have been proposed, but neither of those two new methods considered the spatial structure of the data. If the effects of spatial autocorrelation were included, we predict similar results as seen here.

Just accounting for spatial autocorrelation of samples may not address all of the effects of spatial patterning, which are needed to compare different datasets. The shape of a sample-based rarefaction curve is controlled by several factors, including the extent, grain and number of sampling units (Weins 
1989; Palmer and White 1994; Nekola and White 1999; Dungan et al. 2002). The other key factor is summarized by the first law of geography ("Everything is related to everything else, but near things are more related than distant things", Tobler 1970). This law is apparent as distance-decay patterns at both global and local scales that result in a decrease of compositional similarity with increasing distance (Palmer 2005; Nekola and White 1999; Nekola and Brown 2007; Soininen et al. 2007; Bacaro et al. 2012b). From this pattern, we expect sample-based rarefaction curves to increase faster when sampling units are farther apart (Condit et al. 1996; Palmer et al. 2002; Chiarucci et al. 2008a; Hui 2008) because greater habitat heterogeneity is likely to lead to greater total species richness (Diamond 1988; Palmer et al. 2002). Because of this effect, differences in species richness among data sets could be at least partly due to difference in the extent of the sampling units. (Palmer 2007, McGlinn and Palmer 2011). Similarly, we predict that deviations between RCs and SERs to increase as a direct function of the spatial autocorrelation among sampling units. Methods that account for such effects still need to be developed.

\section{Acknowledgements}

The Authors would like to thank two anonymous reviewers for their constructive comments on an earlier version of the manuscript. This manuscript is based on work done by SMS while serving at the U.S. National Science Foundation. The views expressed in this paper do not necessarily reflect those of the National Science Foundation or the United States Government. DR is partially funded by the FP7 project EU BON. 


\section{References}

Abele, L. G., Walters, K., 1979. Marine benthic diversity: a critique and alternative explanation. J. Biogeogr. 6, 115-126. http://doi.org/10.2307/3038047

Acosta, A., Carranza, M. L., Izzi, C. F., 2009. Are there habitats that contribute best to plant species diversity in coastal dunes?. Biodivers. Conserv. 18, 1087-1098. http://doi.org/10.1007/s10531-0089454-9

Bacaro, G., Santi, E., Rocchini, D., Pezzo, F., Puglisi, L., Chiarucci, A., 2011. Geostatistical modelling of regional bird species richness: exploring environmental proxies for conservation purpose. Biodivers. Conserv. 20, 1677-1694. http://doi.org/10.1007/s10531-011-0054-8

Bacaro, G., Rocchini, D., Ghisla, A., Marcantonio, M., Neteler, M., Chiarucci, A., 2012a. The spatial domain matters: Spatially constrained species rarefaction in a Free and Open Source environment. Ecol. Complex. 12, 63-69. http://doi.org/10.1016/j.ecocom.2012.05.007

Bacaro, G., Rocchini, D., Duprè, C., Diekmann, M., Carnesecchi, F., Gori, V., Chiarucci, A., 2012b. Absence of distance decay in the similarity of plots at small extent in an urban brownfield. Community Ecol. 13, 36-44. http://dx.doi.org/10.1556/ComEc.13.2012.1.5

Brazee, N. J., Lindner, D. L., D’Amato, A. W., Fraver, S., Forrester, J. A., Mladenoff, D. J., 2014. Disturbance and diversity of wood-inhabiting fungi: effects of canopy gaps and downed woody debris. Biodivers. Conserv. 23, 2155-2172. http://dx.doi.org/10.1007/s10531-014-0710-x Cardoso, P., Rigal, F., \& Carvalho, J. C., 2015. BAT-Biodiversity Assessment Tools, an R package for the measurement and estimation of alpha and beta taxon, phylogenetic and functional diversity. Methods Ecol. Evol. 6, 232-236. http://dx.doi.org/10.1111/2041-210X.12310

Chao, A., Jost, L., 2012. Coverage-based rarefaction and extrapolation: standardizing samples by completeness rather than size. Ecology. 93, 2533-2547. http://dx.doi.org/10.1890/11-1952.1

Chao, A., Chiu, C. H., Hsieh, T. C., Davis, T., Nipperess, D. A., Faith, D. P., 2015. Rarefaction and 
extrapolation of phylogenetic diversity. Methods Ecol. Evol. 6, 380-388.

http://dx.doi.org/10.1111/2041-210X.12247

Chiarucci, A., Enright, N.J., Perry, G.L.W., Miller, B.P., Lamont, B.B., 2003. Performance of nonparametric species richness estimators in a high diversity plant community. Divers. Distrib. 9, 283295. http://dx.doi.org/10.1046/j.1472-4642.2003.00027.x

Chiarucci, A., Bacaro, G., Rocchini, D., Fattorini, L., 2008a. Discovering and rediscovering the samplebased rarefaction formula in the ecological literature. Community Ecol. 9, 121-123. http://dx.doi.org/10.1556/ComEc.9.2008.1.14

Chiarucci, A., Bacaro, G., \& Rocchini, D., 2008b. Quantifying plant species diversity in a Natura 2000 network: old ideas and new proposals. Biol. Conserv. 141, 2608-2618. _ http://dx.doi.org/10.1016/j.biocon.2008.07.024

Chiarucci, A., Bacaro, G., Rocchini, D., Ricotta, C., Palmer, M., Scheiner, S., 2009. Spatially constrained rarefaction: incorporating the autocorrelated structure of biological communities into sample-based rarefaction. Community Ecol. 10, 209-214.

http://dx.doi.org/10.1556/ComEc.10.2009.2.11

Chiarucci, A., Bacaro, G., Scheiner, S.M., 2011. Old and new challenges in using species diversity for assessing biodiversity. Philos. Trans. R. Soc. B. 366, 2426-37. http://dx.doi.org/10.1098/rstb.2011.0065 Chiarucci, A., Bacaro, G., Filibeck, G., Landi, S., Maccherini, S., Scoppola, A., 2012. Scale dependence of plant species richness in a network of protected areas. Biodivers. Conserv. 21, 503-516. http://dx.doi.org/10.1007/s10531-011-0196-8

Ciccarelli, D., 2014. Mediterranean coastal sand dune vegetation: influence of natural and anthropogenic factors. Environ. Manage. 54, 194-204. http://dx.doi.org/10.1007/s00267-014-0290-2 Collins, M., Simberloff, D., 2009. Rarefaction and nonrandom spatial dispersion patterns. Environ. Ecol. Stat. 16, 89-103. http://dx.doi.org/10.1007/s10651-007-0051-y 
Colwell, R. K., Mao, C. X., Chang, J., 2004. Interpolating, extrapolating, and comparing incidencebased species accumulation curves. Ecology, 85, 2717-2727. http://dx.doi.org/10.1890/03-0557

Colwell, R. K., Chao, A., Gotelli, N. J., Lin, S. Y., Mao, C. X., Chazdon, R. L., Longino, J. T., 2012. Models and estimators linking individual-based and sample-based rarefaction, extrapolation and comparison of assemblages. J. Plant Ecol. 5, 3-21. http://dx.doi.org/10.1093/jpe/rtr044 Condit, R., Hubbell, S. P., Lafrankie, J. V., Sukumar, R., Manokaran, N., Foster, R. B., Ashton, P. S., 1996. Species-area and species-individual relationships for tropical trees: a comparison of three 50-ha plots. J. Ecol. 84, 549-562. http://dx.doi.org/10.2307/2261477

Cressie, N., 1993. Statistics for spatial data: Wiley series in probability and statistics. WileyInterscience New York, 15, 16.

D’Alessandro, L., Fattorini, L., 2002. Resampling estimators of species richness from presence-absence data: why they don't work. Metron. 61, 5-19.

Diamond, J., 1988. Factors controlling species diversity: overview and synthesis. Ann. Mo. Bot. Gard. 75, 117-129. http://dx.doi.org/10.2307/2399469

Dungan, J. L., Perry, J. N., Dale, M. R. T., Legendre, P., Citron-Pousty, S., Fortin, M.-J., Jakomulska, A., Miriti, M. and Rosenberg, M. S., 2002. A balanced view of scale in spatial statistical analysis. Ecography. 25, 626-640. http://dx.doi.org/10.1034/j.1600-0587.2002.250510.x Engemann, K., Enquist, B.J., Sandel, B., Boyle, B., Jørgensen, P.M., Morueta-holme, N., Peet, R.K., Violle, C., Svenning, J., 2015. Limited sampling hampers "big data" estimation of species richness in a tropical biodiversity hotspot. Ecol. Evol. 5, 807-820. http://dx.doi.org/10.1002/ece3.1405 Engen, S., 1976. A note on the estimation of the species-area curve. J. Cons. Inter. Explor. Mer. 36, 286-288. http://dx.doi.org/10.1093/icesjms/36.3.286

Fairbanks, D.H.K., McGwire, K.C., 2004. Patterns of floristic richness in vegetation communities of California: regional scale analysis with multi-temporal NDVI. Glob. Ecol. Biogeogr. 13, 221-235. 
http://dx.doi.org/10.1111/j.1466-822X.2004.00092.x

Fortin, M. J., Dale, M.R.T., 2009. Spatial autocorrelation in ecological studies: a legacy of solutions and myths. Geogr. Anal. 41, 392-97. http://dx.doi.org/10.1111/j.1538-4632.2009.00766.x

Fortin, M. J., James, P. M., MacKenzie, A., Melles, S. J., Rayfield, B., 2012. Spatial statistics, spatial regression, and graph theory in ecology. Spat. Stat. 1, 100-109.

http://dx.doi.org/10.1016/j.spasta.2012.02.004

Gotelli, N. J., Colwell, R. K., 2001. Quantifying biodiversity: procedures and pitfalls in the measurement and comparison of species richness. Ecol. Lett. 4, 379-391.

http://dx.doi.org/10.1046/j.1461-0248.2001.00230.x

Giesecke, T., Ammann, B., Brande, A., 2014. Palynological richness and evenness: insights from the taxa accumulation curve. Veg. Hist. Archaeobot. 23, 217-28. http://dx.doi.org/10.1007/s00334-014$0435-5$

Hardersen, S., Corezzola, S., 2014. Plot-based butterfly surveys: statistical and methodological aspects. J. Insect Conserv. http://dx.doi.org/10.1007/s10841-014-9728-3 18, 1171-83.

Heilmann-Clausen, J., Christensen, M., 2004. Does size matter?: On the importance of various dead wood fractions for fungal diversity in Danish beech forests. For. Ecol. Manage. 201, 105-117. http://dx.doi.org/10.1016/j.foreco.2004.07.010

Holthe, T., 1975. A method for the calculation of ordinate values of the cumulative species-area curve. J. Cons. Inter. Explor. Mer. 36, 183-184. http://dx.doi.org/10.1093/icesjms/36.2.183

Hui, C., 2008. On species-area and species accumulation curves: A comment on Chong and Stohlgren's index. Ecol. Indic. 8, 327-329. http://dx.doi.org/10.1016/j.ecolind.2007.02.004

Janišová, M., Michalcová, D., Bacaro, G., Ghisla, A., 2014. Landscape effects on diversity of seminatural grasslands. Agric. Ecosyst. Environ. 182, 47-58. http://dx.doi.org/10.1016/j.agee.2013.05.022 
Jung, J. K., Kim, S. T., Lee, S. Y., Park, C. G., Park, J. K., Lee, J. H., 2014. A comparison of diversity and species composition of ground beetles (Coleoptera: Carabidae) between conifer plantations and regenerating forests in Korea. Ecol. Res., 29, 877-887. http://dx.doi.org/10.1007/s11284-014-1175-9

Kobayashi, S., 1974. The species-area relation I. A model for discrete sampling. Res. Popul. Ecol. 15, 223-237.

Kobayashi, S., 1982. The rarefaction diversity measurement and the spatial distribution of individuals. Jpn. J. Ecol. 32, 255-258.

Koellner, T., Hersperger, A. M., Wohlgemuth, T., 2004. Rarefaction method for assessing plant species diversity on a regional scale. Ecography, 27, 532-544. http://dx.doi.org/10.1111/j.0906-

7590.2004.03832.x

Kühn, I., 2007. Incorporating spatial autocorrelation may invert observed patterns. Divers. Distrib. 13, 66-69. http://dx.doi.org/10.1111/j.1472-4642.2006.00293.x

Legendre, P., 1993. Spatial autocorrelation: trouble or new paradigm?. Ecology. 74,1659-1673. http://doi.org/10.2307/1939924

Martellos, S., Attorre, F., 2012. New Trends in Biodiversity Informatics. Plant Biosyst.146,749-751. http://dx.doi.org/10.1080/11263504.2012.740092

Martínez, M. L., Psuty, N. P., 2004. Coastal Dunes: Ecology and Conservation. Berlin, Springer. McGlinn, D. J.,Palmer, M.W., 2011. Quantifying the influence of environmental texture on the rate of species turnover: evidence from two habitats. Plant Ecol. 212, 495-506.

http://dx.doi.org/10.1007/s11258-010-9840-8

Nekola, J. C., White, P. S., 1999. The distance decay of similarity in biogeography and ecology. J. Biogeogr. 26, 867-878. http://dx.doi.org/10.1046/j.1365-2699.1999.00305.x

Nekola, J. C., Brown, J. H., 2007. The wealth of species: ecological communities, complex systems and the legacy of Frank Preston. Ecol. Lett. 10, 188-196. http://dx.doi.org/10.1111/j.1461- 
0248.2006.01003.x

Oksanen, J., Blanchet, F.G., Kindt, R., Legendre, P., Minchin, P.R., O’Hara, R.B., Simpson, G.L., Solymos, P., Stevens, M.H.H., Wagner, H., 2015. Vegan: Community Ecology Package. R Package Version 2.2-1. http://CRAN.R-project.org/package=vegan.

Palmer, M. W., White, P. S., 1994. Scale dependence and the species-area relationship. Am. Nat.144, 717-740.

Palmer, M. W., Earls, P. G., Hoagland, B. W., White, P. S., Wohlgemuth, T., 2002. Quantitative tools for perfecting species lists. Environmetrics. 13, 121-137. http://dx.doi.org/1010.1002/env.516

Palmer, M. W., 2005. Distance decay in an old-growth neotropical forest. J. Veg. Sci. 16, 161-166. http://dx.doi.org/10.1111/j.1654-1103.2005.tb02351.xv

Palmer, M. W., 2007. Species-area curves and the geometry of nature. In: Storch, D., Marquet, P.A. and J. H. Brown, editors. Scaling Biodiversity. Cambridge University Press, Cambridge, pp. 15-31. Ricotta, C., Pavoine, S., Bacaro, G., Acosta, A. T., 2012. Functional rarefaction for species abundance data. Methods Ecol. Evol. 3, 519-525. http://dx.doi.org/10.1111/j.2041-210X.2011.00178.x Roesch, L. F.W., Fulthorpe, R.R., Riva, A., Casella, G., Hadwin, A.K.M., Kent, A.D., Daroub, S.H., Camargo, F.A.O., Farmerie, W,G., Triplett, E.W., 2007. Pyrosequencing enumerates and contrasts soil microbial diversity. ISME J. 1, 283-90. http://dx.doi.org/10.1038/ismej.2007.53

Schneider, K.,Culver, D.C., 2005. Estimating subterranean species richness using intensive sampling and rarefaction curves in a high density cave region in West Virginia. J. Cave Karst Stud.66, 39-45. Siegloch, A. E., Suriano, M., Spies, M., Fonseca-Gessner, A., 2014. Effect of land use on mayfly assemblages structure in Neotropical headwater streams. An. Acad. Bras. Cienc. 86, 1735-1747. http://dx.doi.org/10.1590/0001-3765201420130516

Smith, W., Grassle, J.F., Kravitz, D., 1979. Measures of diversity with unbiased estimates. In: J.F. Grassle, G.P. Patil, W. Smith and C. Taillie (eds), Ecological Diversity in Theory and Practice. 
International Co-operative Publishing House, Fairland (MD). pp. 177-191.

Sogin, M. L., Morrison, H.G., Huber, J.A., Welch, D.M., Huse, S.M., Neal, P.R., Arrieta, J.M., Herndl, G.J., 2006. Microbial diversity in the deep sea and the underexplored 'Rare Biosphere.' Proc. Natl. Acad. Sci. U.S.A. 103, 12115-20. http://dx.doi.org/10.1073/pnas.0605127103

Soininen, J., McDonald, R., Hillebrand, H., 2007. The distance decay of similarity in ecological communities. Ecography. 30, 3-12. http://dx.doi.org/10.1111/j.0906-7590.2007.04817.x

Tobler, W. R., 1970. A computer movie simulating urban growth in the Detroit region. Econ. Geogr. 46, 234-40. http://doi.org/10.2307/143141

Ugland, K. I., Gray, J. S., Ellingsen, K. E., 2003. The species-accumulation curve and estimation of species richness. J. Anim. Ecol. 72, 888-897. http://dx.doi.org/10.1046/j.1365-2656.2003.00748.x Van Der Maarel, E., 2003. Some remarks on the functions of European coastal ecosystems. Phytocoenologia. 33,187-202. http://dx.doi.org/10.1127/0340-269X/2003/0033-0187 Wiens, J. A.,1989. Spatial scaling in ecology. Funct. Ecol. 3, 385-397. http://dx.doi.org/ $10.2307 / 2389612$

Xu, G., Zhong, X., Wang, Y., Warren, A., Xu, H., 2014a. An approach to determining functional parameters of microperiphyton fauna in colonization surveys for marine bioassessment based on rarefaction curves. Environ. Sci. Pollut. Res. 21, 13461-69. http://dx.doi.org/10.1007/s11356-0143293-X

Xu, G., Zhong, X., Wang, Y., Xu, H., 2014b. An approach to detecting species diversity of microfaunas in colonization surveys for marine bioassessment based on rarefaction curves. Mar. Pollut. Bull. 88, 268-74. http://dx.doi.org/10.1016/j.marpolbul.2014.08.032 
Table 1. The total number of sampled plots and diversity values (alpha and gamma) for the Nature 2000 areas compared in this study (for both the worked examples). The common sampling effort is the area of the least sampled data set within a comparison.

\begin{tabular}{|c|c|c|c|c|c|}
\hline Nature Reserve/SCI & $\begin{array}{l}\text { Number } \\
\text { of plots }\end{array}$ & $\begin{array}{c}\text { Total species } \\
\text { richness } \\
\text { (gamma) }\end{array}$ & $\begin{array}{l}\text { Mean plot species } \\
\text { richness (alpha) }\end{array}$ & $\begin{array}{l}\text { Richness at the } \\
\text { common sampling } \\
\text { effort - SER }\end{array}$ & $\begin{array}{l}\text { Richness at the } \\
\text { common sampling } \\
\text { effort - RC }\end{array}$ \\
\hline Migliarino San Rossore & & & & & \\
\hline $\begin{array}{l}\text { Massaciuccoli Regional Park } \\
\text { (MSRM) }\end{array}$ & 675 & 53 & 4.15 & 34.62 & 44.94 \\
\hline Maremma Park (MP) & 305 & 39 & 3.52 & 39.00 & 39.00 \\
\hline $\begin{array}{l}\text { Montagnola Senese } \\
(\mathrm{MNS})\end{array}$ & 137 & 570 & 32.85 & 187.76 & 195.54 \\
\hline $\begin{array}{l}\text { Crete dell'Orcia e del Formone } \\
\text { (FOR) }\end{array}$ & 86 & 472 & 33.37 & 167.44 & 201.35 \\
\hline $\begin{array}{l}\text { Castelvecchio } \\
(\mathrm{CAS})\end{array}$ & 11 & 191 & 42.27 & 191 & 191 \\
\hline
\end{tabular}




\section{Figure Captions}

Figure 1. The locations of the Migliarino-San Rossore-Massaciuccoli Regional Park (MSRM) and the Maremma Regional Park (MP) in the northern and southern parts of Tuscany, Italy, respectively.

Figure 2. Classic and spatially-explicit rarefaction curves for the two coastal dune parks. For the SERs, the Maremma Park (MP) shows on average more species than those collected in an equal-sampled area in the Migliarino San Rossore Masaciuccoli Park (MSRM), the reverse of the pattern of the RCs.

Figure 3. The locations of the Natura 2000 Network in Siena Province and the three SCIs included in example 2 (MNS, FOR and CAS)

Figure 4. Rarefaction curves for the three SCIs (A). SER curves for the three SCIs (B). The rank ordering of the latter curves is the reverse of the former curves. 
Figure 1

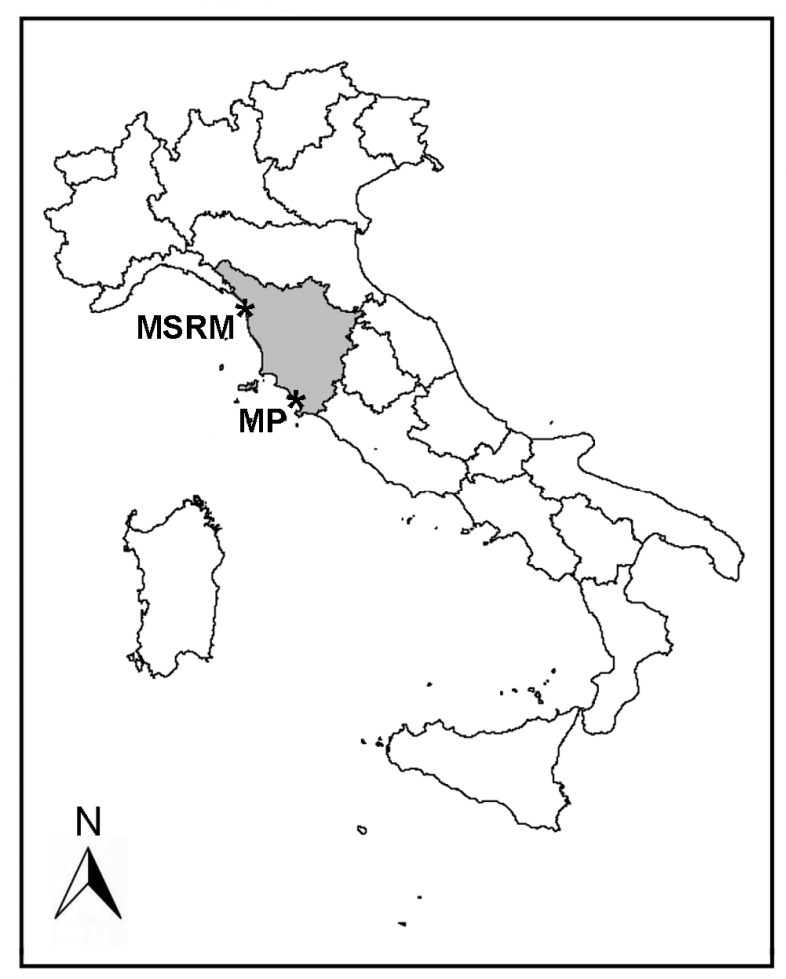


Figure 2

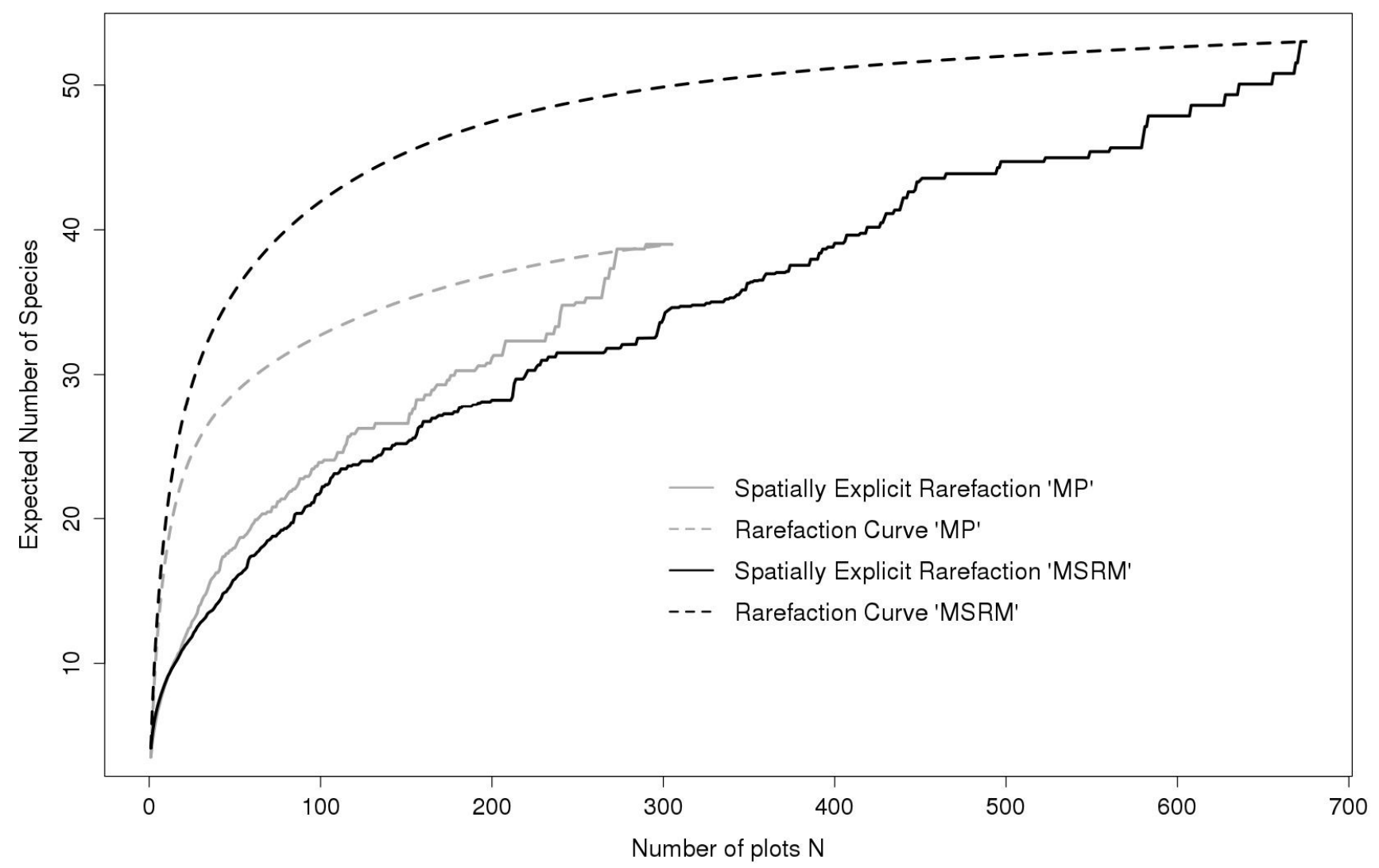


Figure 3

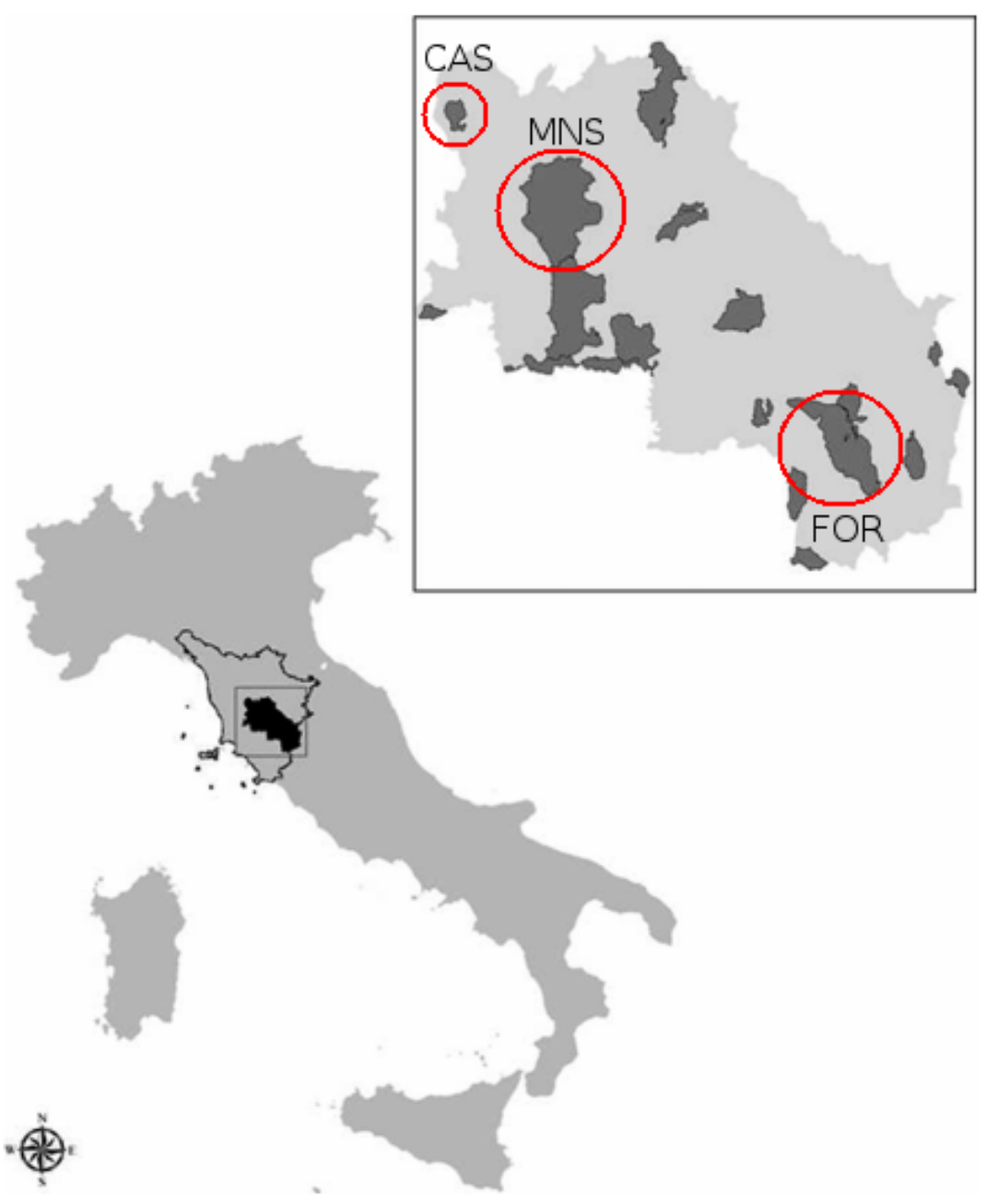


Figure 4

A)

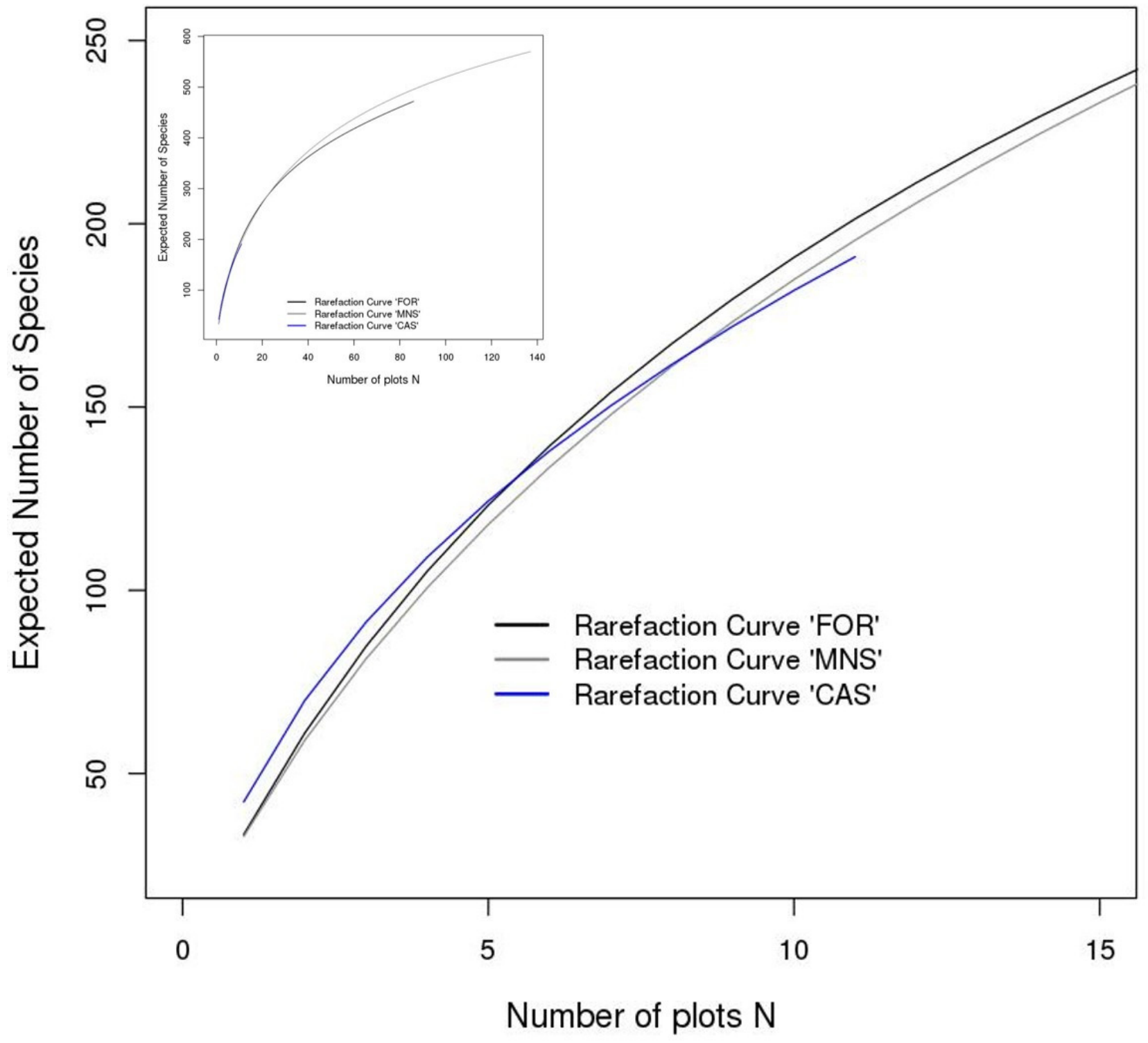


B)

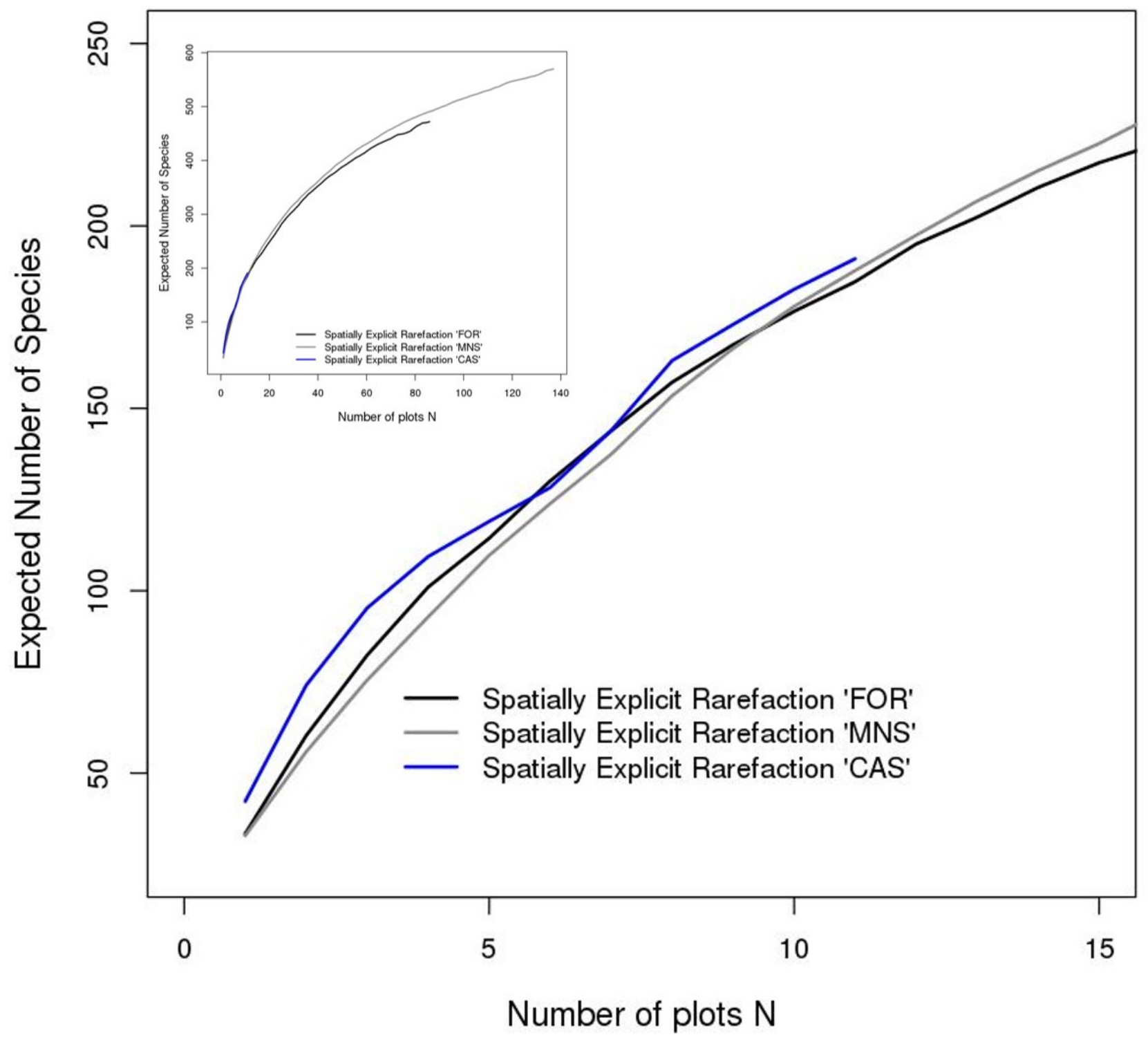

